\title{
Valuation Adjustment Mechanism in M \& A: Application, Analysis and Enlightenment
}

\author{
Tong Zhou \\ Management School, Jinan University, Guangzhou, China \\ Email: zhoutong0730@126.com
}

Received 11 April 2016; accepted 8 May 2016; published 11 May 2016

Copyright (C 2016 by author and Scientific Research Publishing Inc.

This work is licensed under the Creative Commons Attribution International License (CC BY). http://creativecommons.org/licenses/by/4.0/

(c) (i) Open Access

\begin{abstract}
As a creative form of contract, the valuation adjustment mechanism is applied in M \& A for many companies. Measures for Administration of Material Assets Reorganization of Listed Companies, which were adopted on November, 2014, required that listed companies must sign VAM with counterparty when pricing the assets. In $M \& A$, the use of VAM can improve the efficiency and reduce the risk of failure. Based on the case of BlueFocus merged Accurate Sun, this paper thoroughly analyzes the structural design of VAM and its effects. Some suggestions are proposed in this paper in order to explain how to use VAM successfully.
\end{abstract}

\section{Keywords}

\section{Valuation Adjustment Mechanism, M \& A, Performance Compensation Commitment}

\section{Introduction}

In the context of China's economic transformation and under the encouragement of favorable policies national mergers and acquisitions, as well as the implementation of the "going out" strategy, the pace of mergers and acquisitions of Chinese enterprises continue to accelerate. According to statistics, China's M \& A market completed a total of 1929 transactions in 2014, an increase of 56.6\% compared to 1232 in 2013. Although China's M \& A market is very active, the effect of M \& A is not ideal. High M \& A price is the main factor leading to the failure of $\mathrm{M} \& \mathrm{~A}$. The application of the valuation adjustment mechanism in mergers and acquisitions can effectively solve the valuation differences between the two parties and promote the successful acquisition of M \& A transactions. Furthermore, it can improve the success rate of M \& A (Zhang Hongjuan, 2014) [1]. In mergers and acquisitions, the main requirement which was agreed by both parties was the target company's future performance after the acquisition. If it cannot reach the agreed performance conditions, the equity transferor shall give the acquisition of certain compensation in cash or shares, that is the performance compensation com- 
mitment (Lv Changjiang et al., 2014; Cheng Fengzhao et al., 2011) [2] [3]. Measures for Administration of Material Assets Reorganization of Listed Companies, which were adopted on November, 2014, required that listed companies must sign VAM with counterparty when pricing the assets. Visibility, the valuation adjustment mechanism has become an important contractual arrangements to promote the successful rate in mergers and acquisitions of China's listing Corporation.

Since listed on the GEM in Chinain January, 2010, Beijing BlueFocus Brand Management Consulting Co., Ltd. (hereinafter referred to as the "BlueFocus”) has come up a total of the 19 cases of mergers and acquisitions, in which signed the agreement on gambling in $11 \mathrm{M} \& \mathrm{~A}$ activity and the counterparty; it can be said that it is the typical representative on the valuation adjustment mechanism. Based on the case of BlueFocus merged Accurate Sun, I will take a comprehensive analysis of the protocol design and application effect of gambling, and it is conducive to understand in depth of the valuation adjustment mechanism and provide some reference to other enterprises.

\section{Background}

BlueFocus was founded in November 2002, its core business is to provide brand management and advertising services for enterprises. To transform as the leading first-class professional media group company, BlueFocus insists endogenous growth and extension of the M \& A development strategy. Rely on their own internal development, BlueFocus actively strengthen brand influence and core competitiveness of enterprises, improve the management efficiency and the ability of professional services to create value for customers. In terms of mergers and acquisitions in extension, BlueFocus gives full play to the company's capital and the platform edge, and actively looking for marketing industry chain of high-quality enterprises. Through mergers and acquisitions and integration advantages of resources, BlueFocus quickly makes up for its disadvantages in order to achieve development by leaps and bounds. BlueFocus' main business revenue had reached 59.79 billion yuan in 2014, compared to the listed at the beginning of 496 million yuan, the main business income had an increase of more than 10 times.

Beijing Accurate Sun Media Advertising Co., Ltd. (hereinafter referred to as the Accurate Sun), the main businesses are outdoor advertising and distribution of life magazine. In order to create a marketing communications services in the whole industry chain and expand the business, BlueFocus began to merge Accurate Sunin 2011. In July 2011, the BlueFocus announced to raise capital by 174 million yuan to its wholly-owned subsidiary of Shanghai BlueFocus PR Services Co., Ltd. (hereinafter referred to as "Shanghai PR") to invest Accurate Sun [2]. According to a report released by BlueFocus, Shanghai public relations determined the transaction price in accordance with the after tax profits of the commitment which was 32.5 million yuan of 10.5 times price earnings ratio by Accurate Sunin 2011. What's more, additional share up to 35 million yuan invested to the Accurate Sun and Shanghai PR was transferred 1.39 million yuan by the original shareholders of Accurate Sun. After the completion of the capital increase and the acquisition, Shanghai public relations got a total of $51 \%$ of the shares to Accurate Sun. In March 2014, BlueFocus took an acquisition of Accurate Sun's 39.97\% stock rights with 136 million yuan. After the acquisition, BlueFocus hold 90.97\% stake equity of Accurate Sun together. At present, Accurate Sun become the highest gross profit rate in s product line by BlueFocus.

\section{Case Analysis}

\subsection{The Design of the Valuation Adjustment Mechanism}

VAM of BlueFocus and Accurate Sun is composed of three parts: firstly, the future three year commitment to performance and service period of management and prohibition of business strife commitment; secondly, purchase price adjustment scheme of different net profit in 2011; thirdly, the shares of the compensation scheme if net profit did not reach profitability promised more than 97\% in 2012 and 2013. The following analysis will be carried out in turn.

\subsubsection{The Future Three Year Commitment to Performance and Service Period of Management and Prohibition of Business Strife Commitment}

Original shareholders of BlueFocus and Accurate Sun made the following performance compensation commitments in valuation adjustment mechanism: 
(1) Accurate Sun's net profit which was audited and deducted non-recurring gains and losses should not less than 32.5 million yuan in 2011; net profit which was audited and deducted non-recurring gains and losses should not less than 42.25 million yuan in 2012 and not less than 50.7 million yuan with annual growth rate increasing not less than $20 \%$ in 2013 ;

(2) The annual operating net cash flow growth rate of Accurate Sun should not less than $80 \%$ of the growth rate of net profit over the corresponding period in the commitment period (2011-2013). At the same time, in order to guarantee sustainable development and competitive advantage of the corporation, the existing core management team and core business personnel of Accurate Sun committed that they would have been served for Accurate Sun before 2015. In addition, the original shareholders of Accurate Sun still made the prohibition of business strife commitments in VAM, "within five years after they signed the VAM, without prior written permission of Accurate Sun, BlueFocus shall not do self-employed or cooperate with others to engage in identical or similar business, whether directly or indirectly, paid or unpaid, part-time or full-time".

\subsubsection{The Purchase Price Adjustment Scheme}

For mergers and acquisitions when the difference between the actual performance and expected performance of Accurate Sun, the former shareholders of BlueFocus and Accurate Sun agreed the purchase price adjustment plan under the different net profit in 2011 and specific programs as Table 1 shows.

\subsubsection{Equity Compensation Plan}

If the Accurate Sun did not achieve the expected performance goals on net profit in 2012 and 2013, original shareholders of BlueFocus and Accurate Sun agreed to the following share based compensation scheme on valuation adjustment mechanism:

(1) During the commitment period, if net profit of Accurate Sun did not reach profitability promised more than 97\% in 2012 and 2013, the original share holders of Accurate Sun should compensate with shares to BlueFocus. The specific calculation formula is as follows: An annual compensation of the number of shares = (by the end of the current final cumulative net profit commitment - by the end of the current final cumulative actual net income) $\times$ acquisition of the total number of shares (51\% shares of Accurate Sun)/each year net profit of commitment to the sum of the number within the period of compensation-the number of shares which have been compensated.

(2)The specific amount of compensation equity which from the original shareholders of Accurate Sun to BlueFocus was in accordance with the shareholders' equity ratio before investment; at the same time, the shareholders should be jointly and severally liable for equity compensation obligation.

\subsection{The Consequence of Valuation Adjustment Mechanism}

According to financial reports of BlueFocus from 2011 to 2014, net profits of Accurate Sun in the past four years generally showed a trend of rising volatility (as shown in Figure 1). Accurate Sun achieved operating income up to 14,806.49 million yuan and net profit up to 3693.32 million yuan in 2011 which beyond the profit commitment when it was purchased. If we calculated according to the acquisition of BlueFocus that determined the 10.5 times price earnings ratio, Accurate Sun's enterprise value was 38,779.86 million yuan in 2011 and 174 million yuan for investment valuation of BlueFocus, which equity value held by the Accurate Sun added nearly $114 \%$.

Table 1. The plan of price adjustment based on different after-tax profits by BlueFocus in 2011.

\begin{tabular}{|c|c|c|c|}
\hline $\begin{array}{l}\text { Net profit after the audit } \\
\text { in } 2011 \text { by Accurate Sun }\end{array}$ & $\begin{array}{c}\text { Price } \\
\text { earnings ratio(P/E) }\end{array}$ & $\begin{array}{l}\text { Acquisition of } \\
\text { equity this time }\end{array}$ & The purchase price adjustment scheme \\
\hline Net profit $\geq 3250$ & - & $51 \%$ & $\begin{array}{l}\text { Don't need to adjust, carried out in accordance } \\
\text { with the contract which is } 174 \text { million yuan }\end{array}$ \\
\hline $3150 \leq$ net profit $<3250$ & 10.5 & $51 \%$ & Evaluation of investment $=$ Net Profit $\times 10.5$ times $\mathrm{P} / \mathrm{E} \times 51 \%$ \\
\hline $2500 \leq$ net profit $<3150$ & 9 & $51 \%$ & Evaluation of investment $=$ Net Profit $\times 9$ times $\mathrm{P} / \mathrm{E} \times 51 \%$ \\
\hline $2000 \leq$ net profit $<2500$ & 8 & $51 \%$ & Evaluation of investment $=$ Net Profit8times $\mathrm{P} / \mathrm{E} \times 51 \%$ \\
\hline Net profit $<2000$ & - & 0 & $\begin{array}{l}\text { Shanghai public relations has the right } \\
\text { to terminate the investment agreement. }\end{array}$ \\
\hline
\end{tabular}




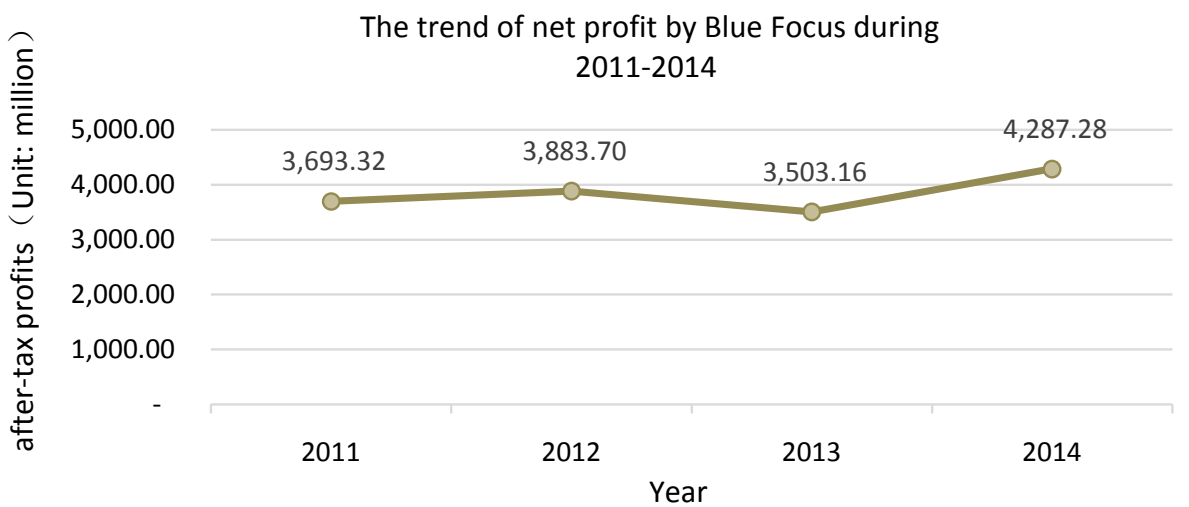

Figure 1. The trend of net profit by BlueFocus during 2011-2014. Source: BlueFocus’ annual reportin 2011-2014.

Influenced by the national standard measures and rectification activities, the entire outdoor advertising industry went into the development of the downturn in 2012 and 2013. The development of Accurate Sun was lower than expected in 2012. Accurate Sun achieved the annual revenue of 14,464.73 million yuan and operating profit of 5215.63 million yuan and net profit of 3883.70 million yuan, an increase of $-2.31 \%, 10.10 \%, 5.15 \%$ respectively. Because the net profit did not reach 4225 million yuan in 2012, according to the shares of the compensation scheme, BlueFocus could acquire 1.87\% shareholders equity from Accurate Sun, the value of it is about 762.56 million yuan.

Furthermore, the development of net profit and growth rate of Accurate Sun was far below than expected in 2013. Accurate Sun achieved the annual revenue of 14198.69millionyuan and operating profit of 4690.92 million yuan and net profit of 3503.16 million yuan, a decrease of $-1.84 \%, 10.06 \%$, 9.80\% respectively. Because the net profit did not reach 5070 million yuan in 2013, according to the shares of the compensation scheme, BlueFocus could acquire $6.72 \%$ shareholders equity from Accurate Sun, the value of it is about 2471.83 million yuan.

The outdoor advertising industry began to fully recover in 2014, and under the tireless efforts and careful performance by management layer, achievements of Accurate Sun improved greatly. Accurate Sun achieved the annual revenue of 15,433.70 million yuan and operating profit of 5230.11 million yuan and net profit of 4287.28 million yuan, an increase of $8.70 \%, 11.49 \%$, and $22.38 \%$ respectively.

\subsection{Application of Valuation Adjustment Mechanism in the Case BlueFocus Merged Accurate Sun}

\subsubsection{Ladder Adjustment Program of Purchase Price Reduce the Risk of M \& A}

Research shows that enterprises usually pay over high prices for target corporation, many M \& A with premium of $48 \%$, and in some case premium even reached $100 \%$. Some companies tend to overestimate the potentiality of transaction, and the high price paid does not always lead to the expected results. High payment price is the main factor leading to the failure of M \& A (Ping Liu, 2004; Bing Tang et al., 2012) [4] [5]. In order to control the premium risk effectively, BlueFocus construct the ladder type investment price adjustment programs in valuation adjustment mechanism, according to net profit performance of Accurate Sun in current year. If Accurate Sun achieve lower net profit, the range of price adjustment gets bigger, that means the actual purchase price BlueFocus pays will be lower. So the financial performance can be closely related to the interests of management, management of Accurate Sun will unite to work hard to achieve performance goal from valuation adjustment mechanism agreement, in order to protect their own interests. BlueFocus transfer a part of the merger premium risk to the original shareholders of Accurate Sun through valuation adjustment mechanism, thereby lowering the risk of $\mathrm{M} \& \mathrm{~A}$ of its own.

\subsubsection{Performance Compensation in the Form of Share Payment Is Conducive to the Transaction Reached}

Performance compensation commitment is one of the most important part of the design of the merger and acqui- 
sition agreement. It can improve the acquisition side ability of choosing and risk judgment of the target corporation, enhance the rate of mergers and acquisitions, and promote the achievement of transactions. In addition, the performance compensation commitment can encourage the management of target corporation to participate harder in the integration process after the acquisition, reducing the merger cost and agency cost (Lv Changjiang et al., 2014). When the target enterprise cannot realize the commitment of VAM, the investment company will obtain performance compensation, mainly in forms of cash and equity. In general, the share payment performance compensation dominates more applications in practice, because most M \& A aim to obtain the control of operation of the target company, and make the target enterprise directly or indirectly under control of their own enterprises. BlueFocus adapt the form of share payment of performance compensation in the VAM with Accurate Sun. on the one hand, it can bring compensation of control power for performance loss to BlueFocus. On the other hand, it will not lead to heavy cash compensation pressure for shareholders of Accurate Sun in the future. This win-win performance compensation scheme contributes to M \& A transactions.

\subsubsection{Comprehensive Performance Measurement Indicators Reduce the Risk of Performance Measurement}

It adapts net profit after deducting non-recurring gains and losses as an indicator of performance measurement for most VAM. Net profit, as the performance index, is concise and accepted by the public, but it will also lead to the pursuit of short-term interests, while ignoring the long-term development for the target enterprise, thus affecting the long-term interests, and it is more vulnerable to human disturbance. Of course, too many indicators will increase the complexity of the VAM, which requires companies to consider the cost and effectiveness of indicators design. BlueFocus adapts two performance measurement indicators, net profit and operating activities cash flow, in the VAM of M \& A with Accurate Sun, which can effectively reduce the performance measurement risk. Compared with the net profit, business activities cash flow is a better indicator reflecting the true operating results, it can reveal the quality of net income and enterprise's working capital management. It usually means enterprise's management enters a virtuous circle if net cash flow of operating activities is positive, and the cash inflow is larger, the management is more stability. Market competition is very fierce in outdoor advertising industry, also it needs a lot of money investment to produce light boxes and other equipment at the first period, so funds have been restricting the rapid development and expansion of Accurate Sun. That shows the cash flow index can effectively measure the possible problems of the enterprise.

\subsubsection{Core Management Team Service Duration Commitment Maintain the Continuity of the Business}

Core management team is the embodiment of the competitiveness of enterprises, is an important driving factor of enterprise value. It does not only determine success or not of the merger integration, but also be related to the future sustainable management ability that how to maintain the stability of the core management team of the target enterprise after the implementation of the merger. Original core management team of target enterprise is familiar with business process, has a better understanding of the industry competition and the change of the market. At the same time, it can avoid causing great psychological impact to employees and is conducive to the effective implementation of $M$ \& A business, organization and cultural integration if retaining the original core management team. The core management team and business personnel made service commitment to December 31, 2014 in VAM agreement for Accurate Sun, which effectively reduced the risk of merger integration of BlueFocus, and improved the continuous operating ability of Accurate Sun.

\section{The Enlightenment of Application of Valuation Adjustment Mechanism in Mergers and Acquisitions}

\subsection{To improve the Efficiency of Acquisition by Valuation Adjustment Mechanism}

Using valuation adjustment mechanism in the acquisition by investors not only can help to improve the efficiency of mergers and acquisitions, reduce transaction costs; at the same time, but also can protect the interests of both sides of mergers and acquisitions. During negotiation process, the equity transferor can deliver information that the company's future business is expected to be good to the purchaser by means of performance compensation commitment in valuation adjustment mechanism, so as to reduce the negotiation costs of companies with high quality during transaction process in merger and acquisition, and can improve the selection ability and 
risk judgment ability by purchaser, then enhance the efficiency of M \& A (Lv Changjiang et al., 2014). After the completion of the merger, valuation adjustment mechanism can reduce the risk of mergers and acquisitions to a certain extent. On the one hand, performance compensation commitment in valuation adjustment mechanism will put pressure on management of target party, thereby encouraging the target company's management to take more efforts to participate in the acquisition of the company after the integration process, then reduce agency cost and running costs in $\mathrm{M} \& \mathrm{~A}$ after the merger and acquisitions. On the other hand, even the target corporation's mismanagement led to the decline in performance after the acquisition, the acquirer can also obtain the corresponding profit compensation which will transfer a part of integration of risk to the selling party.

\subsection{Set Reasonable Performance Goals in Merger and Acquisition}

Introducing valuation adjustment mechanism in $\mathrm{M} \& \mathrm{~A}$, while reducing the investment enterprise pricing and integration risks, but increasing the risk of business failure from over exploitation early of target enterprise. When the performance does not meet expectations, it also increase the risk of successful exercise. Valuation adjustment mechanism, on the one hand, can stimulate the enthusiasm of the target enterprise's management and fully tap the business potential. On the other hand, it may lead to over development on which has high return at present stage under the pressure of performance, thus affect the enterprise long-term profitability. Therefore the enterprise should set reasonable performance goals in merger and acquisition (Wang Lei, 2015) [6]. If the target is too high, it may exist short-term behavior by management in order to achieve the desired performance, it will lead to excessive development by enterprises' potential. In addition, it also lead to non-rational expansion to pursuit large scale and the long-term development of the enterprise will be damaged. If the target is too low, the target enterprise is difficult to feel the pressure, then the expected incentive effect of management cannot play. Zhang Lan, the founder of South Beauty lose control of the enterprise, it is precisely because that year when South Beauty signed valuation adjustment mechanism with CDH investments and setting unreasonable goal.

\subsection{Pay Attention to the Risk Control When Using VAM in the M \& A}

So many factors influence the success of M \& A, the application of VAM agreement does not necessarily reduce the risk of M \& A effectively. To make the risk under control, the acquirer should be integrated with other risk control measures. Firstly, the acquirer should select the target enterprise based on the strategic objectives. Secondly, do deeply investigation of the target enterprise to obtain sufficient information. That is, making comprehensive and deeply investigation about future profitability of the target enterprise from the macro environment, industry development and the enterprise's own operations and other multiple dimensions, to eliminate valuation error as much as possible which comes from blindly optimistic about target enterprise development. At the same time, the acquirer should make some assessments about the management ability and operation ability of the target enterprise management, to determine whether it can steadily promote the development of enterprise in the complex market environment. Finally, we should carefully design the terms of the VAM, reasonable design of exercise standard and the exercise scope, and pay attention to the legal risk the VAM agreement may face to.

\section{Conclusion}

The expansion of domestic financing needs and the constraints of the economic system make the use of the gambling agreement in the enterprise mergers and acquisitions more extensive and efficient. Through the above case study, we find that the key of the successful mergers and acquisitions between BlueFocus and Accurate Sun is the proper valuation of the acquired company, and using the stepwise price scheme; at the same time, we should actively use performance compensation commitment which is an innovative contract tool to improve the efficiency in mergers and acquisitions. In addition, we need pay attention to the correct understanding of the pros and cons of the valuation adjustment mechanism. Besides, the standard should be set as reasonable as possible to protect the interests of both parties, so as to improve the rate of success in mergers and acquisitions.

\section{References}

[1] Zhang, H.J. (2014) Research on the Valuation Adjustment Mechanism Applied in PE and M \& A. University of International Business and Economics, Beijing. 
[2] Lv, C.J. and Han, H.B. (2014) VAM, Synergy and Distribution of Gains from M \& A. Audit \& Economy Research, No. 6, 3-13.

[3] Cheng, F.C. and Liu, J.P. (2011) Research on Pricing of Mergers and Acquisitions of Listed Companies. Accounting Research, No, 11, 40-46.

[4] Liu, P. (2004) The Trap of Synergistic Effect and Its Prevention in M \& A. Economic Forum, No. 10, 63-64.

[5] Tang, B., Tian, L.W. and Cao, J.Z. (2012) Howto Create Value in M \& A-Based on the Case of China Eastern Airlinemerges Shanghai Airline. Management World, No. 11, 1-8.

[6] Wang, L. (2015) Research on Earnouts Applied in M \& A. Beijing Jiaotong University, Beijing. 